\title{
МОРФОМЕТРИЯ ГЕПАТОЦИТОВ НА РАЗЛИЧНЫХ ЭТАПАХ РАЗВИТИЯ ЦЫПЛЯТ-БРОЙЛЕРОВ КРОССА АРБОР АЙКРЕЗ
}

\author{
G.V. Sulaymanova, N.V. Donkova
}

\section{THE MORPHOMETRY OF HEPATOCYTES AT DIFFERENT STAGES OF THE DEVELOPMENT OF CHICKEN-BROILERS OF ARBOR IKREZ CROSS}

Сулайманова Гульнара Владимировна - канд. ветеринар. наук, доц. каф. внутренних незаразных болезней, акушерства и физиологии сельскохозяйственных животных Красноярского государственного аграрного университета, г. Красноярск.

E-mail: sulaimanova5@yandex.ru

Донкова Наталья Владимировна - д-р ветеринар. наук, проф., зав. каф. анатомии, патологической анатомии и хирургии Красноярского государственного аграрного университета, г. Красноярск. E-mail:dnv-23@mail.ru

Цель исследования - изучение возрастной динамики морфометрических показателей гепатоцитов иыплят-бройлеров кросса Арбор Айкрез на разных этапах развития. Объектом исследования послужила печень птицы семи возрастных груnп с суточного до 42-суточного возраста. Гистологические препараты печени готовили по общепринятым методикам, окрашивали гематоксилином и эозином. Морфоометрию гепатоцитов проводили с помощью программы Cito 2.0. У иыплят-бройлеров геnатоциты полигональной формы, ядра окрашиваются ярко базофильно, имеют овальную или округлую форму. По перифрерии печеночной дольки видны портальные триады, включающие в себя междольковые вену, артерию и желчный проток. В суточном возрасте у цыплят-бройлеров площадь гепатоцитов составила 23,66 $\pm 1,06$ мкм²;

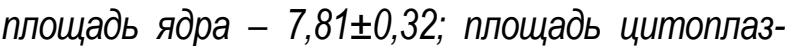

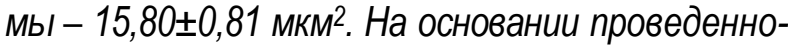
го исследования установлено, что рост и иитодифреренцировка гепатоцитов у иыплятбройлеров кросса Арбор Айкрез за период выращивания с суточного до 42-суточного возраста имеет ряд закономерностей. Наиболее интенсивный рост площади гепатоцитов во всех трех зонах печеночной дольки отмечает-
Sulaymanova Gulnara Vladimirovna - Cand. Veterinary Sci., Assoc. Prof., Chair of Internal Noncontagious Diseases, Obstetrics and Physiology of Farm Animals, Krasnoyarsk State Agrarian University, Krasnoyarsk.

E-mail: sulaimanova5@yandex.ru

Donkova Natalya Vladimirovna - Dr. Veterinary Sci., Prof., Head, Chair of Anatomy, Pathological Anatomy and Surgery, Krasnoyarsk State Agrarian University, Krasnoyarsk.

E-mail: dnv-23@mail.ru

ся до 14-суточного возраста: в первую неделю увеличение площади гепатощитов составило 33,69 \%, во вторую неделю - 37,46 \%. В первую неделю жизни наиболее интенсивно увеличивается площадь ядер гепатоцитов и дости-

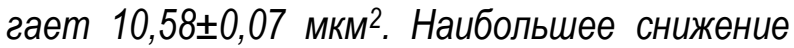
ядерно-цитоплазматического отношения, отражающего степень цитодиференцировки гепатоцитов цыплят-бройлеров кросса Арбор Айкрез, отмечалось с 7-е по 14-е сутки развития. Значимых различий в скорости роста площади ядер и цитоплазмы гепатоцитов в различных зонах классической дольки (перивенулярной, интермедиальной, перипортальной) не выявлено.

Ключевые слова: морфометрия, гепатоциты, кросс Арбор Айкрез, цыплята-бройлеры.

The aim of the research was to study the age dynamics of morphometric indicators of hepatocytes of broiler chickens of Arbor Ikrez cross at different stages of their development. The object of the study was the liver of the poultry of seven age groups from 1 day to 42 days of age. Histological liver preparations were made according to conventional methods, stained with hematoxylin and eosin. The morphometry of hepatocytes was performed using "Cito 2.0" program. In broiler chickens, the 
hepatocytes were polygonal in shape; the nuclei were brightly colored basophilically with oval or rounded shape. On the periphery of hepatic lobule, portal triads were visible, including interlobular vein, artery, and bile duct. At the age of 1 day of broiler chickens, the area of hepatocytes was $23.66 \pm 1.06$ $\mathrm{mm}^{2}$, the core area was $7.81 \pm 0.32 \mathrm{~mm}^{2}$, and the cytoplasm area was $15.80 \pm 0.81 \mathrm{~mm}^{2}$. Based on the conducted research, it was found out that the growth and cytodiferentiation of hepatocytes in broiler chickens of Arbor Aikrez cross during growing period from one day to 42 days of age had a number of regularities. The most intensive growth of the hepatocyte area in all three zones of the hepatic lobule was observed up to 14 days of age: in the first week, the increase in the area of hepatocytes was $33.69 \%$, in the second week - $37.46 \%$. In the first week of life the area of hepatocyte nuclei increased most intensively and reached $10.58 \pm 0.07 \mathrm{~mm}^{2}$. The greatest reduction of nuclear-cytoplasmic ratio, reflecting the degree of cytodifferentiation hepatocytes of Arbor Aikrez chickens-broilers, was noted from 7 to 14 days of the development. There were no significant differences in the growth rate of the nuclei area and the cytoplasm of hepatocytes in different zones of classical lobule (perivenular, intermediate, and periportal).

Keywords: morphometry, hepatocytes, cross Arbor Aikrez, broiler chickens.

Ведение. Птицеводство является наиболее устойчивой и динамично развивающейся отраслью агропромышленного комплекса нашей страны, которая за короткий период сумела обеспечить население качественной мясной и яичной продукцией. В птицеводческих комплексах содержится большое количество птиц, которое необходимо рассматривать как совокупный биологический организм, требующий внимательного отношения к своему здоровью $[5,6]$. В последние годы в мясном птицеводстве появляются новые кроссы цыплят-бройлеров, обладающих интенсивным ростом живой массы, такие как Арбор Айкрез. Особенности роста, развития и цитодиферинцировки внутренних органов у данного кросса мало изучены.

Важную роль в защите организма от экзогенных и эндогенных токсинов играет печень, которая, по мнению Л.И. Дроздовой (2010), является живой лабораторией оценки качества кормления и содержания птицы [1]. Морфологическая зрелость печени обеспечивает полноценное функционирование организма. Функция печени сложна и многообразна, орган обезвреживает экзогенные и эндогенные ксенобиотики, секретирует желчь и другие жизненно важные вещества (желчные кислоты, билирубин и холестерин, гормоны и ферменты, активно участвующие в пищеварении) [2-4].

Структурной единицей печени, как известно, является классическая печеночная долька, в центре которой расположена центральная вена, от которой радиально отходят ряды гепатоцитов. В печеночной дольке различают три зоны: перивенулярную, интермедиальную и перипортальную. Перипортальные гепатоциты отличаются от клеток перивенулярной зоны по ряду ключевых ферментов, рецепторов и субклеточных структур, в связи с чем имеют различные функциональные способности [7], что отражается на структуре и морфометрической характеристике гепатоцитов разных зон печеночной дольки. В условиях интенсивного воздействия на птицефабриках экзогенных фракторов (высокоэнергетические корма, лекарственные препараты) важным является оценка возрастной динамики гепатоцитов в зависимости от расположения в классической дольке печени у цыплятбройлеров кросса Аброр Айкрез.

В доступной нам литературе данных о возрастной динамике морфометрических показателей гепатоцитов у цыплят-бройлеров кросса Арбор Айкрез мы не обнаружили.

Цель исследования: изучение морфометрических показателей гепатоцитов цыплятбройлеров кросса Арбор Айкрез на различных этапах развития.

Материалы и методы исследования. Исследование проводилось на кафедре анатомии, патологической анатомии и хирургии Красноярского государственного аграрного университета. С целью изучения возрастных микроструктурных особенностей гепатоцитов цыплят-бройлеров кросса Арбор Айкрез были отобраны кусочки печени от цыплят семи возрастных групп: суточных, 7-, 14-, 21-, 28-, 35- и 42-суточных. Для гистологического исследования кусочки печени размером 0,5 на 0,5 см фиксировали в $10 \%$ растворе нейтрального формалина, затем промывали под проточной водой, обезвоживали в спиртах возрастающей крепости и заливали в парафин. Гистологические срезы готовили на санном микротоме с электроприводом и микро- 
процессорным управлением МЗП-1 «Техом» и окрашивали гематоксилином и эозином. Микрофотосьемку микропрепаратов проводили на тринокулярном микроскопе Levenhuk. Морфометрию гепатоцитов различных зон печеночной дольки проводили с помощью программы Cito 2.0, выделяя перивенулярную, интермедиальную и перипортальную зоны. Площадь гепатоцитов и их ядер высчитывали по формуле эллипса. Цифровые данные обрабатывали статистически с использование t-критерия Стьюдента.

Результаты исследования. Снаружи печень покрыта капсулой, от которой отходят прослойки междольковой соединительной ткани, что у цыплят-бройлеров развита слабо и видна лишь в области портальной триады, в области центральной вены соединительная ткань не видна, поэтому классическая долька на гистологических препаратах у птицы выражена слабо. Границы классической дольки печени у цыплятбройлеров определяли по расположению портальной триады. Печеночная долька имеет полигональную форму, в ее центре располагается центральная вена безмышечного типа округлой или овальной формы, иногда в ней просматриваются овальной формы ядросодержащие эритроциты. У цыплят суточного возраста гепатоциты в печени расположены хаотично, печеночные балки не видны. С 7-суточного возраста на микропрепаратах печени цыплят-бройлеров видны радиально расположенные тяжи, со- стоящие из двух рядов гепатоцитов и формирующие в направлении от центральной вены к периферии три зоны: перивенулярную, интермедиальную и перипортальную (рис. 1). На границе печеночных долек видны портальные триады, включающие в себя междольковую вену, междольковую артерию и междольковый желчный проток. Самым крупным сосудом триады является вена, которая имеет самый больший диаметр, спавшийся просвет и слабовыраженную медию. Интима вены портальной триады ровная, гладкая, выстлана эндотелиоцитами, медиа представлена гладкими миоцитами, наружная оболочка - слаборазвитой соединительной тканью.

Артерия триады имеет слабовыраженный просвет, интима извилистая, ядра эндотелиоцитов выступают в просвет сосуда. Медиа представлена преимущественно пучком гладких миоцитов с примесью единичных эластических волокон, адвентиция развита умеренно. Желчный проток триады представляет собой сосуд мелкого диаметра, выстланный кубическим эпителием с округлыми крупными базофильными ядрами. На микропрепаратах печени цыплятбройлеров в портальной триаде часто встречаются два желчных протока и две артерии.

Гепатоциты, входящие в состав печеночного тяжа, являются паренхиматозными элементами печени, у цыплят-бройлеров кросса Арбор Айкрез они полигональной фрормы (рис. 2).

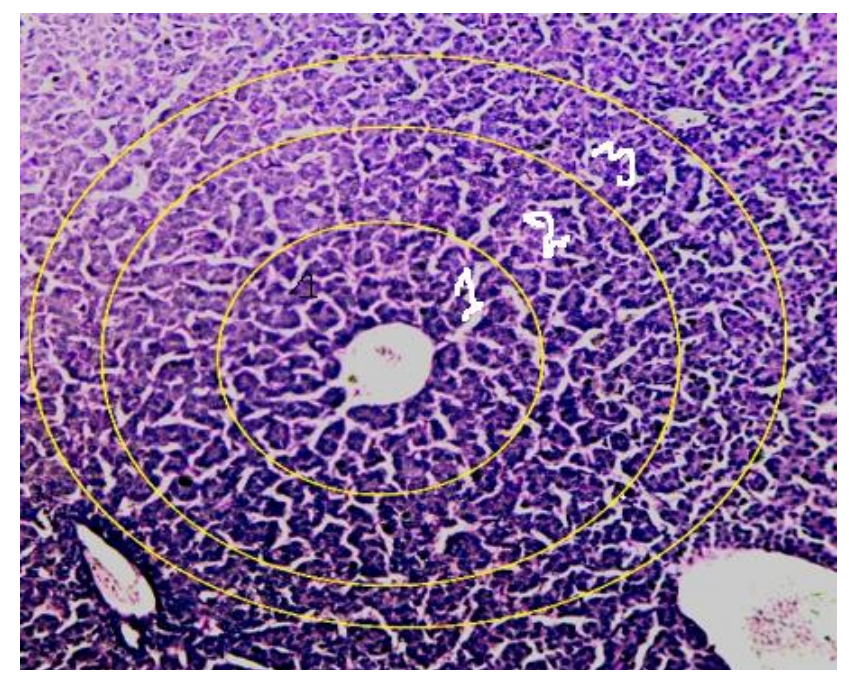

Puc. 1. Печень 7-суточного цыпленка. Печеночная долька: а - перивенулярная зона,

б - интермедиальная зона, в - перипортальная зона

(окраска - гематоксилин и эозин. Ув.: об. 10 ×) 


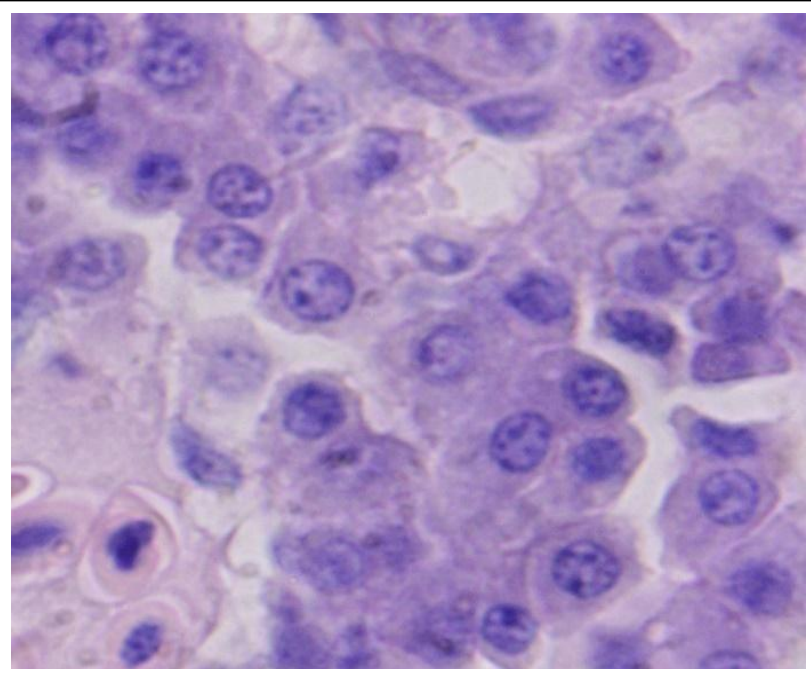

Puc. 2. Печень 21-суточного цыпленка (окраска гематоксилин и эозин. Ув.: об. 90х)

В печени суточных цыплят тяжи печеночных клеток не сформированы. На микропрепаратах печени имеются зоны с низкодиффреренцированными клетками и нечетко выраженными цитолеммами, но большая часть гепатоцитов име- ет границы, что позволило нам измерить их площадь. Установлено, что площадь гепатоцитов всех зон классической дольки печени с возрастом увеличивается. Данные представлены в таблице 1.

Таблица 1

\section{Динамика площади гепатоцитов в разных зонах печеночной дольки у цыплят-бройлеров кросса Арбор Айкрез, мкм²}

\begin{tabular}{|c|c|c|c|c|}
\hline \multirow{2}{*}{$\begin{array}{c}\text { Возраст } \\
\text { цыплят, сут }\end{array}$} & \multicolumn{3}{|c|}{ Зона классической дольки печени } & \multirow{2}{*}{$\begin{array}{c}\text { Среднее } \\
\text { по всем зонам }\end{array}$} \\
\hline & Перивенулярная & Интермедиальная & Перипортальная & \\
\hline $1-e$ & $22,16 \pm 0,83$ & $23,75 \pm 2,66$ & $24,58 \pm 1,16$ & $23,66 \pm 1,06$ \\
\hline $7-e$ & $32,13 \pm 1,38^{* * *}$ & $33,29 \pm 0,85^{* *}$ & $30,18 \pm 1,20^{* *}$ & $31,63 \pm 0,92^{* * *}$ \\
\hline 14-e & $42,27 \pm 2,35^{\star \star}$ & $42,79 \pm 2,39^{\star *}$ & $44,50 \pm 2,64^{* \star *}$ & $43,48 \pm 2,34^{* * *}$ \\
\hline $21-e$ & $40,26 \pm 2,15$ & $45,40 \pm 1,31$ & $40,94 \pm 1,88$ & $40,26 \pm 2,15$ \\
\hline $28-e$ & $44,05 \pm 2,45$ & $44,05 \pm 2,45$ & $43,00 \pm 2,07$ & $42,56 \pm 1,35$ \\
\hline $35-e$ & $52,40 \pm 3,17$ & $44,83 \pm 2,72$ & $47,36 \pm 4,14$ & $47,87 \pm 2,60$ \\
\hline $42-e$ & $38,90 \pm 4,23$ & $47,47 \pm 1,52$ & $47,30 \pm 2,10$ & $45,58 \pm 1,33$ \\
\hline
\end{tabular}

Здесь и далее. Уровень достоверности различий каждой возрастной группы по сравнению с предыдущей: *P $<0,05$; ${ }^{* *} P<0,01 ;{ }^{* * *} P<0,001$.

Как показали морфометрические исследования, в суточном возрасте площадь гепатоцитов у цыплят-бройлеров была наименьшей и по всем

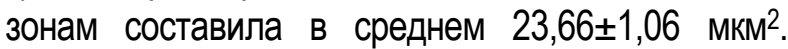
С суточного до 7-суточного возраста птицы площадь гепатоцитов увеличилась по всем зонам в среднем на 33,69 \% ( $<<0,001)$, с 7суточного до 14-суточного возраста - на $37,46 \%$ $(\mathrm{P}<0,001)$. В каждой возрастной группе площадь гепатоцитов в перивенулярной, интермедиальной и перипортальной зонах классической печеночной дольки не имела достоверных различий.

При окраске срезов печени цыплятбройлеров гематоксилином и эозином ядра гепатоцитов имели овальную или округлую форму, окрашивались ярко базофильно, на фоне более бледной кариоплазмы просматривались 1-2 ядрышка, хроматин преимущественно сосредоточен у кариолеммы. Ядрышки в ядрах гепатоцитов более отчетливо визуализируются на 21-е сутки постэмбрионального развития. 
Площадь ядра в гепатоцитах суточной птицы в среднем во всей печеночной дольке составила 7,81 $\pm 0,32$ мкм² (рис. 2). К 7-суточному возрасту площадь ядра гепатоцитов достоверно увеличилась в перивенулярной зоне на 49,66 \%, в интермедиальной зоне - на 35,81\%, в перипортальной - на 35,47\%. В последующие возрастные периоды у цыплят-бройлеров достоверного увеличения площади ядер гепатоцитов не отмечалось.

\section{Динамика площади ядра в разных зонах печеночной дольки у цыплят-бройлеров кросса Арбор Айкрез, мкм²}

Таблица 2

\begin{tabular}{|c|c|c|c|c|}
\hline \multirow{2}{*}{$\begin{array}{c}\text { Возраст } \\
\text { цыплят, сут }\end{array}$} & \multicolumn{3}{|c|}{ Зона классической дольки печени } & \multirow{2}{*}{$\begin{array}{c}\text { Среднее } \\
\text { по всем зонам }\end{array}$} \\
\hline & Перивенулярная & Интермедиальная & Перипортальная & \\
\hline $1-e$ & $7,35 \pm 0,34$ & $7,68 \pm 0,74$ & $7,79 \pm 0,42$ & $7,81 \pm 0,32$ \\
\hline $7-e$ & $11,0 \pm 0,54^{\star \star *}$ & $10,43 \pm 0,50^{*}$ & $10,32 \pm 0,75^{*}$ & $10,58 \pm 0,41^{* * *}$ \\
\hline 14-e & $10,60 \pm 0,88$ & $11,12 \pm 0,80$ & $12,47 \pm 1,20$ & $11,53 \pm 0,97$ \\
\hline $21-e$ & $9,22 \pm 0,74$ & $10,18 \pm 0,39$ & $9,92 \pm 0,41 \mathrm{H}$ & $9,22 \pm 0,77$ \\
\hline $28-e$ & $9,50 \pm 0,68$ & $9,50 \pm 0,68$ & $10,14 \pm 0,53$ & $9,57 \pm 0,33$ \\
\hline $35-e$ & $11,59 \pm 0,67$ & $9,80 \pm 0,57$ & $10,83 \pm 0,74$ & $10,72 \pm 0,49$ \\
\hline $42-e$ & $9,86 \pm 0,98$ & $10,57 \pm 1,38$ & $10,41 \pm 1,01$ & $10,68 \pm 1,21$ \\
\hline
\end{tabular}

у цыплят-бройлеров площадь цитоплазмы гепатоцитов достоверно увеличивалась с момента вылупления до 14-суточного возраста (табл. 3). Так, площадь цитоплазмы увеличилась с суточного до 7-суточного возраста на
39,24 \%, с 7-го по 14-го возраста - на 45,68 \%. В последующие возрастные периоды достоверного изменения площади гепатоцитов и цитоплазмы мы не выявили.

\section{Динамика площади цитоплазмы в разных зонах печеночной дольки у цыплят-бройлеров кросса Арбор Айкрез, мкм²}

\begin{tabular}{|c|c|c|c|c|}
\hline \multirow{2}{*}{$\begin{array}{c}\text { Возраст } \\
\text { цыплят, сут }\end{array}$} & \multicolumn{3}{|c|}{ Зона классической дольки печени } & \multirow{2}{*}{$\begin{array}{c}\text { Среднее } \\
\text { по всем зонам }\end{array}$} \\
\hline & Перивенулярная & Интермедиальная & Перипортальная & \\
\hline $1-e$ & $14,78 \pm 0,57$ & $16,17 \pm 1,94$ & $16,46 \pm 0,88$ & $15,80 \pm 0,81$ \\
\hline $7-\mathrm{e}$ & $22,91 \pm 0,86^{* * *}$ & $22,54 \pm 0,88^{*}$ & $21,67 \pm 1,69^{*}$ & $22,00 \pm 0,57^{* * *}$ \\
\hline 14-e & $31,73 \pm 1,95^{* *}$ & $31,79 \pm 2,18^{* *}$ & $32,47 \pm 2,18^{* *}$ & $32,05 \pm 1,84^{* * *}$ \\
\hline $21-e$ & $31,00 \pm 1,62$ & $36,22 \pm 1,17$ & $30,92 \pm 1,88$ & $31,00 \pm 0,62$ \\
\hline $28-e$ & $34,54 \pm 1,87$ & $34,54 \pm 1,87$ & $32,79 \pm 1,86$ & $32,69 \pm 0,79$ \\
\hline $35-e$ & $40,74 \pm 2,85$ & $35,42 \pm 2,40$ & $35,36 \pm 3,00$ & $37,91 \pm 2,65$ \\
\hline $42-e$ & $32,63 \pm 1,17^{*}$ & $37,12 \pm 1,13$ & $36,86 \pm 2,06$ & $35,29 \pm 1,38$ \\
\hline
\end{tabular}

Ядерно-цитоплазматическое отношение (ЯЦО) - это важнейшая морфологическая характеристика, которая отражает отношение ядра к цитоплазме, характеризующая уровень об- мена веществ и степень диффференциации клеток [3]. Возрастная динамика ЯЦО у цыплятбройлеров кросса Арбор Айкрез представлена в таблице 4. 


\section{Динамика ядерно-цитоплазматического отношения в зонах печеночной дольки у цыплят-бройлеров кросса Арбор Айкрез}

\begin{tabular}{|c|c|c|c|c|}
\hline \multirow{2}{*}{$\begin{array}{c}\text { Возраст } \\
\text { цыплят, сут }\end{array}$} & \multicolumn{3}{|c|}{ Зона классической дольки печени } & \multirow{2}{*}{$\begin{array}{c}\text { Среднее } \\
\text { по всем зонам }\end{array}$} \\
\hline & Перивенулярная & Интермедиальная & Перипортальная & \\
\hline $1-e$ & $0,55 \pm 0,03$ & $0,53 \pm 0,03$ & $0,56 \pm 0,04$ & $0,55 \pm 0,02$ \\
\hline $7-e$ & $0,52 \pm 0,03$ & $0,51 \pm 0,02$ & $0,51 \pm 0,03$ & $0,51 \pm 0,02$ \\
\hline 14-e & $0,36 \pm 0,03^{* *}$ & $0,41 \pm 0,04^{*}$ & $0,42 \pm 0,04$ & $0,39 \pm 0,03^{\star *}$ \\
\hline $21-e$ & $0,32 \pm 0,02$ & $0,31 \pm 0,02^{*}$ & $0,35 \pm 0,03$ & $0,32 \pm 0,02$ \\
\hline $28-e$ & $0,30 \pm 0,02$ & $0,30 \pm 0,02$ & $0,35 \pm 0,02$ & $0,32 \pm 0,01$ \\
\hline $35-e$ & $0,30 \pm 0,02$ & $0,29 \pm 0,03$ & $0,33 \pm 0,02$ & $0,31 \pm 0,01$ \\
\hline $42-e$ & $0,30 \pm 0,05$ & $0,30 \pm 0,04$ & $0,31 \pm 0,04$ & $0,31 \pm 0,04$ \\
\hline
\end{tabular}

Нами установлено, что максимальное значение ЯЦО имело в гепатоцитах цыплят суточного

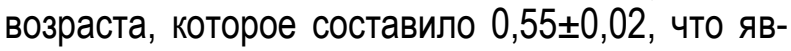
ляется закономерным, поскольку высокие показатели ЯЦО свойственны молодым, малодифференцированным клеткам. Показатель ЯЦО в гепатоцитах птицы достоверно снижался во вторую неделю постэмбрионального развития

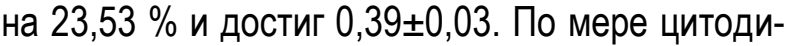
ференцировки гепатоцитов происходит уменьшение ЯЦО, что свидетельствует об их дефинитивном созревании. Наиболее интенсивное снижение ЯЦО в гепатоцитах отмечается до 14ти суточного возраста. К моменту убоя цыплятбройлеров, т. е. к 42-м суткам выращивания птицы ЯЦО в гепатоцитах составило 0,31 0,04 , что на 43,64 \% ниже, чем в гепатоцитах цыплят суточного возраста.

Выводы. На основании проведенных исследований установлено, что рост и цитодиференцировка гепатоцитов у цыплят-бройлеров кросса Арбор Айкрез за период выращивания с суточного до 42-суточного возраста имеет ряд закономерностей. Наиболее интенсивный рост площади гепатоцитов во всех трех зонах печеночной дольки отмечается до 14-суточного возраста: в первую неделю увеличение площади гепатоцитов составило 33,69 \%, во вторую неделю - 37,46 \%. В первую неделю жизни наиболее интенсивно увеличивается площадь ядер гепатоцитов и достигает $10,58 \pm 0,07$ мкм² $^{2}$. Наибольшее снижение показателя ЯЦО, отражающего степень цитодиференцировки гепатоцитов цыплят-бройлеров кросса Арбор Айкрез, отмечалось с 7-х по 14-е сут развития. Значимых различий в скорости роста площади ядер и цитоплазмы гепатоцитов в различных зонах классической дольки (перивенулярной, интермедиальной, перипортальной) не выявлено.

\section{Литература}

1. Дроздова Л.И., Кундрюкова У.И. Печень птицы - живая лаборатория оценки качества кормления и содержания // Аграрный вестник Урала. 2010. № 5. С. 68-71.

2. Курилкин В.В. Морфофуункциональные показатели печени кур в постэмбриональном онтогенезе: дис. ... канд. ветеринар. наук: 06.02.01. - М., 2011. - $130 \mathrm{C}$.

3. Селянский В.М. Анатомия и фризиология сельскохозяйственной птицы. М.: Колос, 1980. $280 \mathrm{c}$.

4. Сулайманова Г.В., Донкова Н.В. Морфометрические особенности печени кур кросса Арбор Айкрес // Вестник КрасГАУ. 2019. № 4. С. 75-80.

5. Ткачев Д.А. Постнатальный морфогенез печени у кур кросса Иза- Браун: авторефр. дис. ... канд. ветеринар. наук. Брянск, 2007. $21 \mathrm{c}$.

6. Турицына Е.Г. Иммунодесрициты птиц: этиология, патогенез, морфологическая диагностика, способы коррекции / Краснояр. гос. аграр. ун-т. Красноярск, 2010. 208 с.

7. Jungermann K., Kietzmann $T$. Zonation of parenchymal and nonparenchymal metabolism in liver // Annu. Rev. Nutr. 1996. № 16. S. 179-203. 


\section{Literatura}

1. Drozdova L.I., Kundrjukova U.I. Pechen' pticy - zhivaja laboratorija ocenki kachestva kormlenija i soderzhanija // Agrarnyj vestnik Urala. 2010. № 5. S. 6871.

2. Kurilkin V.V. Morfofunkcional'nye pokazateli pecheni kur $\mathrm{V}$ postjembrional'nom ontogeneze: dis. kand. veterinar. nauk: 06.02.01. M., 2011. $130 \mathrm{~s}$.

3. Seljanskij V.M. Anatomija i fiziologija sel'skohozjajstvennoj pticy. - M.: Kolos, 1980. $-280 \mathrm{~s}$.
4. Sulajmanova G.V., Donkova N.V. Morfometricheskie osobennosti pecheni kur krossa Arbor Ajkres // Vestnik KrasGAU. 2019. № 4. S. 75-80.

5. Tkachev D.A. Postnatal'nyj morfogenez pecheni u kur krossa Iza- Braun: avtoref. dis. ... kand. veterinar. nauk. Brjansk, 2007. $21 \mathrm{~s}$.

6. Turicyna E.G. Immunodeficity ptic: jetiologija, patogenez, morfologicheskaja diagnostika, sposoby korrekcii / Krasnojar. gos. agrar. un-t. Krasnojarsk, 2010. 208 s.

7. Jungermann K., Kietzmann T. Zonation of parenchymal and nonparenchymal metabolism in liver // Annu. Rev. Nutr. 1996. № 16. S. 179-203. 